\title{
Science for Global Sustainability: Toward a New Paradigm
}

William C. Clark, Paul J. Crutzen, and Hans J. Schellnhuber

CID Working Paper No. 120

March 2005

Science, Environment and Development Group, CID

(C) Copyright 2005 William C. Clark, Paul J. Crutzen, Hans J. Schellnhuber, and the President and Fellows of Harvard College
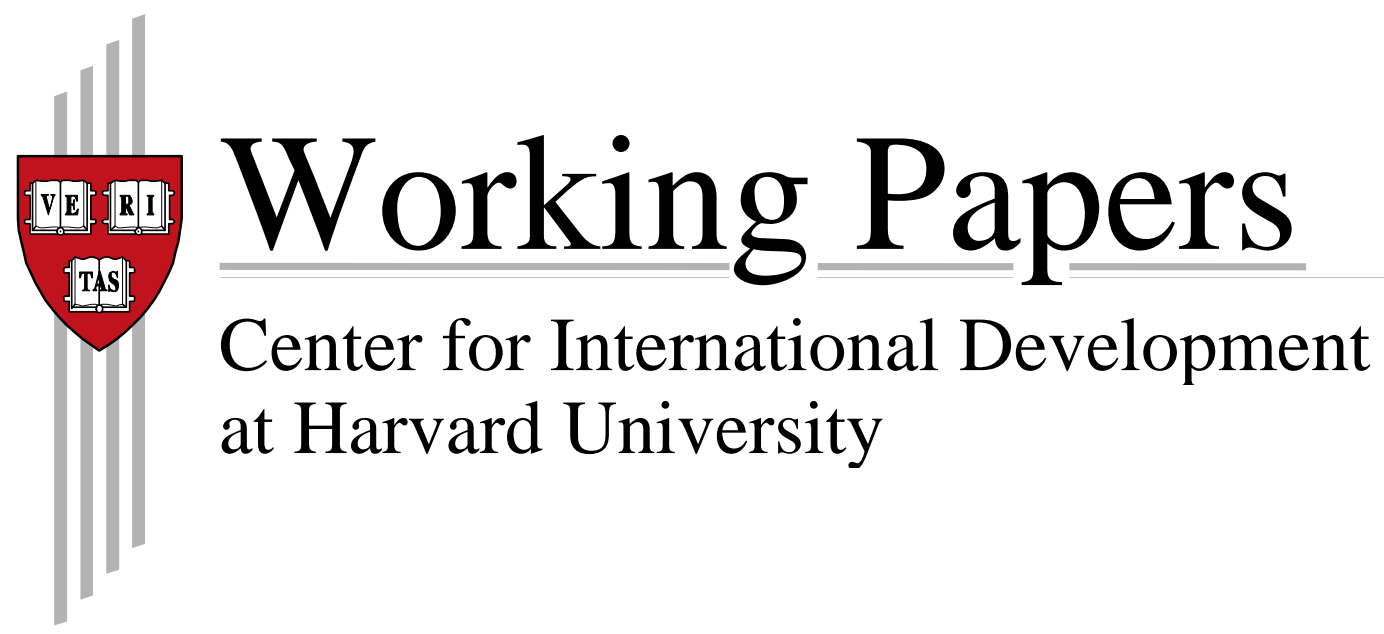


\title{
Science for Global Sustainability: Toward a New Paradigm
}

\author{
William C. Clark, Paul J. Crutzen, and Hans J. Schellnhuber
}

\begin{abstract}
This paper provides a context for the Dahlem Workshop on "Earth System Analysis for Sustainability." The authors begin by characterizing the contemporary epoch of Earth history in which humanity has emerged as a major-and uniquely self-reflexive-geological force. They turn next to the extraordinary revolution in our understanding of the Earth system that is now underway, pointing out how it has built on and qualitatively extended the approaches that have served science and society so well since the first Copernican revolution. The authors then discuss the novel challenges posed by the urgent need to harness science and other forms of knowledge in promoting a worldwide sustainability transition that enhances human prosperity while protecting the Earth's life-support systems and reducing hunger and poverty. Finally, the authors provide an overview of how the contributions to this Dahlem Workshop addressed the themes and challenges outlined in this introductory chapter.
\end{abstract}

Keywords: Dahlem Workshop, sustainability science, sustainable development, sustainability transition, Earth system analysis, Earth system science, integrated systems, global environmental change, science and technology, Wissenschaft, adaptive management, social learning, vulnerability, resilience, knowledge systems, guidance systems, institutions

JEL codes: Q01, Q56, O19, O31, O32, O33, Z13, F02, H87, I3 


\section{Citation, Context, and Program Acknowledgements}

This paper may be cited as:

Clark, William C., Paul J. Crutzen, and Hans J. Schellnhuber. 2005. "Science for Global Sustainability: Toward a New Paradigm.” CID Working Paper No. 120. Cambridge, MA: Science, Environment and Development Group, Center for International Development, Harvard University; also published as Ch. 1 in Earth System Analysis for Sustainability. Edited by Hans Joachim Schellnhuber, Paul J. Crutzen, William C. Clark, Martin Claussen, and Hermann Held. Cambridge, MA: MIT Press.

It is available at http://www.cid.harvard.edu/cidwp/120.htm. Comments are welcome and may be directed to the authors. William Clark can be contacted via email at william_clark@harvard.edu or at the John F. Kennedy School of Government, Harvard University, 79 JFK Street, Cambridge, MA 02138, USA. Paul Crutzen can be contacted via email at air@mpch-mainz.mpg.de or at the Max-Planck-Institute for Chemistry, Department of Atmospheric Chemistry, P.O. Box 3060, D-55020 Mainz, Germany. Hans Joachim Schellnhuber can be contacted via email at h.j.schellnhuber@uea.ac.uk, at the Tyndall Center for Climate Change Research, School of Environmental Sciences, University of East Anglia, Norwich NR4 7TJ, UK, or at the Potsdam Institute for Climate Impact Research (PIK), P.O. Box 601203, 14412 Potsdam, Germany.

A Dahlem Workshop entitled "Earth System Analysis for Sustainability” was held 25-30 May 2003 in Berlin, Germany and co-chaired by the authors of this working paper. The resulting book, in which this paper serves as the introductory chapter, explores the question of whether the unprecedented humanoriginated changes transforming the ecosphere today will end a 10,000-year period of climate stability. The book focuses on four topics: long-term geosphere-biosphere interaction and the possibility of using extrasolar planets to test various geophysical hypotheses; the Quaternary Earth System's modes of operation; current planetary dynamics under human pressure; and transition to global sustainability. It analyzes the driving forces behind global change and uses this knowledge to propose principles for global stewardship.

The Science, Environment and Development Group at Harvard's Center for International Development collaborates internationally on a variety of research projects and outreach activities that seek to improve society's understanding of interactions between human development and the natural environment, and to harness that understanding in support of a transition towards sustainability. The Group builds bridges between the local, place-based character of many sustainability challenges and the increasingly global context within which solutions to those challenges must be shaped. It is concerned with the role of "partnerships" among governments, civil society, the private sector, and academia in shaping solutions.

Further information on the Science, Environment and Development Group at Harvard's Center for International Development can be found at http://www.ksg.harvard.edu/sed or by contacting Nancy Dickson at nancy_dickson@harvard.edu. Further information about the Dahlem Workshop can be found at http://www.fu-berlin.de/dahlem/. 



\title{
1 \\ Science for Global Sustainability \\ Toward a New Paradigm
}

\author{
W.C. Clark ${ }^{1}$, P. J. Crutzen ${ }^{2}$, and H. J. Schellnhuber ${ }^{3}$ \\ ${ }^{1}$ J.F. Kennedy School of Government, Harvard University, \\ Cambridge, MA 02138, U.S.A. \\ ${ }^{2}$ Max-Planck-Institut für Chemie, Otto-Hahn-Institut, 55020 Mainz, Germany \\ ${ }^{3}$ Tyndall Center for Climate Change Research, School of Environmental Sciences, \\ University of East Anglia, Norwich NR4 7TJ, U.K. and Potsdam Institut for \\ Climate Impact Research (PIK), P.O. Box 601203, 14412 Potsdam, Germany
}

\section{INTRODUCTION}

This paper provides a context for the Dahlem Workshop on Earth System Analysis for Sustainability. We begin by characterizing the contemporary epoch of Earth history in which humanity has emerged as a major - and uniquely self-reflexive - geological force. We turn next to the extraordinary revolution in our understanding of the Earth system that is now underway, pointing out how it has built on and qualitatively extended the approaches that have served science and society so well since the first Copernican revolution. We then discuss the novel challenges posed by the urgent need to harness science and other forms of knowledge in promoting a worldwide sustainability transition that enhances human prosperity while protecting the Earth's life-support systems and reducing hunger and poverty. Finally, we provide an overview of how the contributions to this Dahlem Workshop addressed the themes and challenges outlined in this introductory chapter.

\section{THE ANTHROPOCENE}

We live today in what may appropriately be called the "Anthropocene" - a new geologic epoch in which humankind has emerged as a globally significant and potentially intelligent - force capable of reshaping the face of the planet (Crutzen 2002).

\section{History of the Idea}

Humans have doubtless been altering their local environments since arriving on the scene as a distinct species several hundred thousand years ago. Our debut as 
major actors on the global stage - actors comparable in influence to the classic roles played by erosion, volcanism, natural selection, and the like - is a much more recent phenomenon. This dates back at most several thousand years, but has accelerated greatly in scope and influence over the last several centuries (Ruddiman 2003).

Self-awareness by humans of our role as global transformers is younger still. Seminal contributions began to emerge in the nineteenth century, for example Ansichten der Natur by the German geographer Alexander von Humboldt (1808) and The Earth as Modified by Human Action by the American diplomat George Perkins Marsh (1864/1965). By 1873, the Italian geologist Antonio Stoppani was describing humanity's activities as a "new telluric force, which in power and universality may be compared to the greater forces of Earth" (Stoppani 1873). The theme was subsequently developed and given a much wider audience by the Russian geochemist V.I. Vernadsky in a series of lectures on the "biosphere" given at the Sorbonne in the early 1920s (Vernadsky 1998/1926, 1945). The last half century witnessed an accelerating program of scientific studies (e.g., Thomas 1956; Steffen et al. 2004) that have broadened and deepened our understanding of what Turner et al. (1990) have convincingly characterized as an "Earth transformed by human action."

Along with humanity's growing awareness of its role in transforming the Earth has come a growing recognition that how we use this awareness will shape the Earth's future, and our own. Vernadsky (1998/1926) himself speculated on "...the direction in which the processes of evolution must proceed, namely towards increasing consciousness and thought, and forms having greater and greater influence on their surroundings." Along with his French colleagues, the scientist and mystic P. Teilhard de Chardin and philosopher Édouard Le Roy, Vernadsky (1998/1926) coined the term "noösphere" to suggest a biosphere in which not only human action, but human thought and reflection on the consequences of its actions, would come to play a determinative role. Rapidly expanding efforts to manage the impact of human activities on the global environment show that humanity is taking seriously the idea and implications of a noösphere (Brown 1954; Clark 1989; Caldwell and Weiland 1996; Mitchell 2003).

The most recent big idea to emerge in the history of the Anthropocene is that of "sustainability" - a normative concept regarding not merely what is, but also what ought to be the human use of the Earth (Kates 2001). The concern for using our understanding of human impacts on the Earth's environment to help guide our use of the Earth in "sustainable" directions can be traced back to early work on the conservation of renewable resources. Much of that discussion was cast in terms of a contest between environmental protection and human development. By the late 1970s, however, the inadequacies of this traditional competitive framing were becoming increasingly clear. The World Conservation Strategy, published by the International Union for the Conservation of Nature (IUCN) in 1980 , reframed the modern sustainability debate by arguing explicitly that goals 
for protecting the Earth's lands and wildlife could not be realized except through strategies that also addressed the improvement of human well-being in conservation areas. This view was formulated for environmental protection, in general, and the Earth, as a whole, in the report of the World Commission on Environment and Development (WCED - the Brundtland Commission) on Our Common Future, released in 1987.

The Brundtland Commission argued for advancing a global program of sustainable development "that meets the needs of the present without compromising the ability of future generations to meet their own needs" (WCED 1987). Its conceptualization of the sustainability challenge was adopted by many world leaders in Rio de Janeiro at the UN Conference on Environment and Development (UNCED) in 1992, and was diffused broadly within governmental, business, and academic communities over the next decade. U.N. Secretary-General Kofi Annan (2000) reflected a growing consensus when he wrote in his Millennium Report to the General Assembly that "freedom from want, freedom from fear, and the freedom of future generations to sustain their lives on this planet" are the three grand challenges facing the international community at the dawn of the twenty-first century. By the time of the World Summit on Sustainable Development, held in Johannesburg in 2002, achieving sustainability had become a "high table" goal in international affairs, and on many regional, national, and local political agendas.

The need for harnessing science and technology in support of efforts to achieve the goal of environmentally sustainable human development in the Anthropocene was generally recognized at the Johannesburg Summit. How this might be accomplished was not. Exploring the options and opportunities for promoting such efforts was the central objective of this Dahlem Workshop on "Earth System Analysis for Sustainability."

\section{State of the Transformation}

An up-to-date understanding of how humans actions are in fact transforming the Anthropocene is the necessary foundation for any serious effort to harness science and technology for sustainability. The recent report of the world scientific community's decade-long research program on Global Environmental Change and the Earth System (Steffen et al. 2004) provides such a foundation.

Drawing from the works of hundreds of researchers, the "Global Change" study (Steffen et al. 2004; Chapter 3) concluded that perhaps 50\% of the world's ice-free land surface has been transformed by human action; the land under cropping has doubled during the past century at the expense of forests, which declined by $20 \%$ over the same period. More than half of all accessible freshwater resources have come to be used by humankind. Fisheries remove more than $25 \%$ of the primary production of the oceans in the upwelling regions and $35 \%$ in the temperate continental shelf regions (Pauly and Christensen 1995). 
More nitrogen is now fixed synthetically and applied as fertilizers in agriculture than is fixed naturally in all terrestrial ecosystems. Over-application of nitrogen fertilizers in agriculture and its concentration in domestic animal manure have led to eutrophication of surface waters and groundwater in many locations around the world. They also lead to the microbiological production of $\mathrm{N}_{2} \mathrm{O}$, a greenhouse gas and a source of $\mathrm{NO}$ in the stratosphere where it is strongly involved in ozone chemistry.

Humanity's exploitation of fossil fuels that were generated over several hundred million years has resulted in a large pulse of air pollutants. The release of $\mathrm{SO}_{2}$ to the atmosphere by coal and oil burning is at least two times larger than the sum of all natural emissions, which occur mainly as marine dimethylsulfide from the oceans. The oxidation of $\mathrm{SO}_{2}$ to sulfuric acid has led to acidification of precipitation and lakes, causing forest damage and fish death in biologically sensitive regions, such as Scandinavia and the northeast section of North America. As a result of substantial reduction in $\mathrm{SO}_{2}$ emissions, the situation in these regions has improved somewhat over the last decades. However, the problem has gotten worse in East Asia.

The release of NO into the atmosphere from fossil fuel and biomass combustion is likewise larger than the natural inputs, adding to rainwater acidity and giving rise to photochemical ozone ("smog") formation in extensive regions of the world.

Humanity is also responsible for the presence of many toxic substances in the environment and even some, the chlorofluorocarbon gases $\left(\mathrm{CFCl}_{3}\right.$ and $\left.\mathrm{CF}_{2} \mathrm{Cl}_{2}\right)$, which are not toxic at all, have nevertheless led to the Antarctic springtime "ozone hole"; the CFCs would have destroyed much more of the ozone layer if international regulatory measures had not been taken to end their production by 1996. However, due to the long residence times of CFCs, it will take at least another 4-5 decades before the ozone layer will have recovered. The discovery of maximum reduction in stratospheric ozone came as a total surprise. It was not predicted and happened in a section of the atmosphere, where ozone loss was thought to be impossible and the furthest away from the regions of CFC releases to the atmosphere.

Due to fossil-fuel burning, agricultural activities, deforestation, and intensive animal husbandry, several climatically important "greenhouse" gases have substantially increased in the atmosphere over the past two centuries: $\mathrm{CO}_{2}$ by more than $30 \%$ and $\mathrm{CH}_{4}$ by even more than $100 \%$, contributing substantially to the observed global average temperature increase by about $0.6^{\circ} \mathrm{C}$, which has been observed during the past century. According to a report by the Intergovernmental Panel of Climate Change (IPCC 2001, p. 10): "There is new and stronger evidence that most of the warming observed over the last 50 years is attributable to human activities."

There is no question that humanity has done quite well by its transformation of the planet. Supported by great technological and medical advancements as 
well as by access to plentiful natural resources, we have colonized most places on Earth and even set foot on the Moon. The transformations of the last century helped humanity to increase the amount of cropland by a factor of 2 , the number of people living on the planet by a factor of 4 , water use by a factor of more than 8 , energy use by a factor of 16 , and industrial output by a factor of more than 40 (McNeill 2000; see Chapter 14, Table A-1, this volume). The quality of human life also increased, with average life expectancy up more than $40 \%$ in the last 50 years, literacy up more than $20 \%$ in the last 35 years, and substantial improvements in the female/male ratio in primary education, the number of people living in democratic countries, and the increased commitment of the international community to protect civilians from internal conflict and to defend the rights of national minorities (Kates and Parris 2003). The uneven distribution of these increases, their tenuous character, and the continued suffering of peoples left, or falling, behind are stark reminders that much more remains to be done. However, the fact remains that humanity, on average, has done very well indeed through its continuing transformation of the Earth. The question is whether past trends of increasing prosperity can be broadened and sustained as the Anthropocene matures.

\section{Prognosis for the Future}

The prognosis for continued and sustainable improvements in human well-being on a transformed planet Earth is, at best, guarded. The U.S. National Academy of Sciences has concluded that over the next half century, human population can be expected to increase by perhaps $50 \%$. Associated with such an increase, the demand for food production could well increase by $80 \%$, for urban infrastructure by $100 \%$, and for energy services by substantially more than $200 \%$ (NRC 1999, p. 70). The resulting intensification of pressures on an already stressed biosphere could be overwhelming.

For example, depending on the scenarios of future energy use and model uncertainties, the increasing emissions and resulting growth in atmospheric concentrations of $\mathrm{CO}_{2}$ are estimated to cause a rise in global average temperature by $1.4-5.8^{\circ} \mathrm{C}$ during the present century, accompanied by sea-level rise of $9-88 \mathrm{~cm}$ (and 0.5-10 m until the end of the current millennium). According to Hansen (2004), considering only the warming of the globe over the past 50 years plus the warming already "in the pipeline" - together more than one degree Celsius the Earth will return halfway to temperature conditions of the last interglacial, the Eemian (120 to 130 thousand years ago), when global sea levels were 5-6 meters higher than at present. Greater warming is, however, expected if humanity cannot drastically curtail the emissions of $\mathrm{CO}_{2}$ and other greenhouse gases. The impact of current human activities is projected to last over very long periods. According to Loutre and Berger (2000), because of past and future anthropogenic emissions of $\mathrm{CO}_{2}$, climate may depart significantly from natural over the next 50,000 years. 
After a careful examination of the environmental, social, and economic implications of these and other intensifying transformations, the Academy concluded that "current trends of population and habitation, wealth and consumption, technology and work, connectedness and diversity, and environmental change are likely to persist well into the $\left(21^{\text {st }}\right)$ century and could significantly undermine the prospects for sustainability. If they do persist, many human needs will not be met, life-support systems will be dangerously degraded, and the numbers of hungry and poor will increase" (NRC 1999, p. 101). Based on its view of plausible social and technical options for breaking these trends, however, the Academy noted that "a successful transition toward sustainability is possible over the next two generations. This transition could be achieved without miraculous technologies or drastic transformation of human societies.... What will be required, however, are significant advances in basic knowledge, in the social capacity and technological capabilities to utilize it, and in the political will to turn this knowledge to action" (NRC 1999, p. 160).

Are such advances in knowledge and its application possible? Will the Anthropocene simply turn out to be a very short era in which humanity blindly careens forward, continuing to transform the Earth until the planet loses its capacity to support us? Or might humanity rise to the challenge posed by Vernadsky, becoming the reflective, thinking, and proactive agent that transforms the biosphere into a noösphere, and consciously striving to shape a niche for ourselves in a sustainable Anthropocene? The answers to such questions will hinge in no small part on future developments of the sciences of the Earth system, and of sustainability. We turn to the opportunities and challenges facing such developments in the next sections of this chapter.

\section{EARTH SYSTEM SCIENCE}

In its quest to become an intelligent agent in and of the Anthropocene, what are the prospects for humanity developing a robust scientific understanding of the complex Earth system of which it is such a rambunctious part?

\section{The Second Copernican Revolution}

In 1530, Nikolaus Copernicus published his book De Revolutionibus Orbium Coelestium, which set the stage for the development of modern science. Not only was the Earth finally put in its correct astrophysical context, but the first principles of "exact and objective" reasoning, ultimately triumphing in the Enlightenment, were also established: The perception of cosmic reality became dominated by the clockwork metaphor, assigning a regular trajectory governed by eternal physical laws to each particle in the Universe. The production of wisdom became dominated by the curiosity-driven mode, confronting the brightest minds with the ultimate riddles of creation in splendid isolation from 
sociopolitical interests - and from each other. Thus the great Copernican Revolution generated a paradigm of science, where the lonely scholar wrestles with Nature in order to snatch some of her secrets encoded in mathematical formulae of utter beauty.

In 2001, delegates from more than 100 countries participating in the four big international research programs on global environmental change endorsed the "Amsterdam Declaration," which formally established the "Earth System Science Partnership" (Moore et al. 2002) and set the stage for what one might call a second Copernican Revolution (Schellnhuber 1999). This novel revolution is deeply rooted in the original one, yet transcends it in several crucial ways:

1. The scientific eye is re-directed from outer space to our "living Earth" (Lovelock 2003), which operates as one single dynamical system far from thermodynamical equilibrium.

2. The scientific ambition is re-qualified by fully acknowledging the limits of cognition as highlighted by the notorious uncertainties associated with nonlinearity, complexity, and irreproducibility (Schellnhuber 2002); if the Earth system is a clockwork at all, then it is an organismic one that baffles our best anticipatory capacities.

3. The scientific ethos is re-balanced at last by accepting that knowledge generation is inextricably embedded in the cultural-historical context (Nowotny et al. 2001) - there is nothing wrong with being particularly curious about the items and issues that matter most for society and with recognizing that the coveted borderlines between observing subjects and scrutinized objects have often been mere constructions of a preposterous reductionism. Thus the research community becomes part of their own riddles, the research specimens become part of their own explanations, and co-production becomes the (post)normal way of coping with the cognitive "challenges of a changing Earth" (Steffen et al. 2002).

The very fact that the Amsterdam Declaration resulted from an intricate cooperative process - and not from one ingenious idea of a stand-alone intellectual giant - adequately reflects the co-productive mode that will be instrumental for the much-debated "new contract between science and society" (see discussion below). Even a superficial look at the current state and dynamics of our planet indicates that the sustainability of modern civilization is at risk without such a contract. Actually the threats associated with anthropogenic global warming have already sparked the creation of an unprecedented format for the dialogue between researchers and decision makers, and for the co-establishment of global assessment power, namely the IPCC. This panel is a genuine post-Copernican creation that provides a panoramic, yet fragmentary and fuzzy, view of the myriads of facets involved in the climate change problem. This view, in turn, provides the most credible basis for international adaptive management strategies which have to be implemented and revised in phase with the highly 
irregular advancement of our pertinent knowledge as based, inter alia, on the monitoring of our own ecological footprints.

\section{A Hilbertian Program for Earth System Science}

Although humanity has been capable of transforming the Earth through a deluge of entangled but uncoordinated actions, it was evidently intellectually unprepared to do so or to cope with the consequences at the level of whole-systems wisdom. Nobody had a grand plan for planetary refurbishment after World War II, and nobody anticipated the scientific challenges arising when this refurbishment actually happened without plan, rhyme, or reason. (Annan 2000).

We are learning by "doing global change." The post-Copernican process, as epitomized (and accelerated) by the Amsterdam Declaration, keeps on setting unprecedented research agendas in unprecedented ways. Of course, there are Copernican role models for this, like David Hilbert's monumental program for the advancement of mathematics in the twentieth century (Hilbert 1901). This program basically consisted of a rather eclectic list of 23 problems to be solved by the pertinent community that had gathered at the World Conference for Mathematics in Paris in 1900. Some of Hilbert's riddles still stand unbroken by scientific siege or even unassailed by strong intellectual forces, but their very formulation launched a collective campaign venturing towards the borders of formal reasoning. Recently, the international Earth system science community formulated their own Hilbertian Program (Steffen et al. 2004, p. 265; Schellnhuber and Sahagian 2002), which lists 23 crucial questions that need to be addressed for global sustainability and may well drive global change research towards, and beyond, the limits of conventional scholarship raised to the planetary level.

The Hilbertian program for the advancement of Earth system understanding in the (first decades of the) twenty-first century emerged quite unconventionally, namely from an extended email conference organized in 2001 by GAIM (Sahagian and Schellnhuber 2002) - the transdisciplinary think-tank of the International Geosphere-Biosphere Programme (IGBP). The list of questions (see Box 1.1) is arranged in four blocks emphasizing a predominantly analytical, methodological, normative, and strategic character, respectively, and strongly reflects the three "post-Copernican" features discussed earlier.

To illustrate this, let us choose and briefly explain one question from each of the blocks. We begin with Question 3, which asks about the "critical elements" in the Earth system, i.e., those components, areas, processes, patterns, or substances within the planetary machinery that behave like control knobs: their alteration triggers persistent (if not irreversible), large-scale (if not global) change. There is clearly an analogy to the human body, where the destruction of delicate organs or the suppression of trace hormones can bring about significant transmutation, if not exitus.

A biogeophysical subset of the Earth's critical elements is compiled in the map of Figure 1.1. Its entries are underpinned by research results of rather 
Box 1.1 A Hilbertian program for Earth system science.

\section{Analytical Questions:}

1. What are the vital organs of the ecosphere in view of operation and evolution?

2. What are the major dynamical patterns, teleconnections, and feedback loops in the planetary machinery?

3. What are the critical elements (thresholds, bottlenecks, switches) in the Earth System?

4. What are the characteristic regimes and timescales of natural planetary variability?

5. What are the anthropogenic disturbance regimes and teleperturbations that matter at the Earth-system level?

6. Which are the vital ecosphere organs and critical planetary elements that can actually be transformed by human action?

7. Which are the most vulnerable regions under global change?

8. How are abrupt and extreme events processed through nature-society interactions?

\section{Normative Questions:}

15. What are the general criteria and principles for distinguishing nonsustainable and sustainable futures?

16. What is the carrying capacity of the Earth?

17. What are the accessible but intolerable domains in the coevolution space of nature and humanity?

18. What kind of nature do modern societies want?

19. What are the equity principles that should govern global environmental management?

\section{Operational Questions:}

9. What are the principles for constructing "macroscopes", i.e., representations of the Earth system that aggregate away the details while retaining all systems-order items?

10. What levels of complexity and resolution have to be achieved in Earth System modelling?

11. Is it possible to describe the Earth system as a composition of weakly coupled organs and regions, and to reconstruct the planetary machinery from these parts?

12. What might be the most effective global strategy for generating, processing and integrating relevant Earth system data sets?

13. What are the best techniques for analyzing and possibly predicting irregular events?

14. What are the most appropriate methodologies for integrating natural science and social science knowledge?

\section{Strategic Questions:}

20. What is the optimal mix of adaptation and mitigation measures to respond to global change?

21. What is the optimal decomposition of the planetary surface into nature reserves and managed areas?

22. What are the options and caveats for technological fixes like geoengineering and genetic modification?

23. What is the structure of an effective and efficient system of global environment and development institutions?

varying conclusiveness, and the collections are far from being complete. In fact, new suspects are identified by global change research almost every year, such as the Indian monsoon, which may be pushed onto a roller-coaster dynamics by the combined driving forces of anthropogenic global warming, anthropogenic regional air pollution, and anthropogenic local land surface transformation (Zickfeld 2003). 


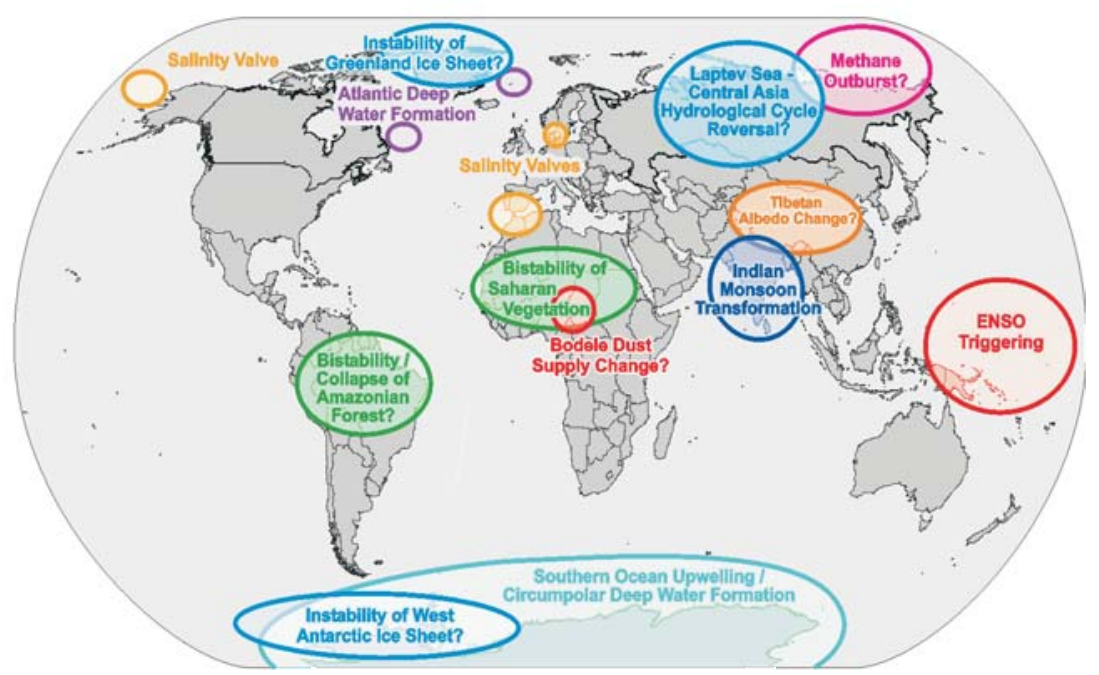

Figure 1.1 Geographically explicit switch and choke elements in the Earth system.

While the criticality analysis of the planetary ecosphere is making good progress and promises to support, in the not-too-distant future, global stewardship with a comprehensive list of neuralgic items that must be treated with utter caution, the complementary criticality analysis of the anthroposphere has not yet begun: What are the irreplaceable components of the global industrial metabolism? On which agricultural region will future world food production crucially depend? Are there institutions that can preserve/establish social cohesion and international equity throughout the globalization process? Which of the current megacities are bound to implode ultimately, and where will the new planetary centers of knowledge production lie? What technologies have the potential to transform radically humanity's interactions with its natural resources and its life-support systems? Genuine Earth system analysis for sustainability needs to address all of the questions, but there will be no quick answers.

The next illustration concerns Question 14, which asks about the best methodologies for integrating the Earth system knowledge produced by both the natural sciences and the social sciences. This question is part of a much wider, long-standing debate that attempts to bridge the "hard" and the "soft" disciplines. In recent years, two diametrically opposite schemes - perceived by many as battering rams rather than bridges - have been put forward: The first "integrating" strategy is the formalization of the social sciences along the lines of mathematical physics as epitomized by the invention of "econophysics" (see, e.g., the review articles in Bunde et al. 2002). This development reflects an epistemological attitude anticipated by David Hume in 1748 as follows: "The great advantage of the mathematical sciences above the moral consists in this, that the ideas of the former are always clear and determinate." A popular and 
sweeping state-of-the art account is given by Philip Ball (2004), who tries to demonstrate that socioeconomic behavior can be described, in principle, by Newtonian-like equations of motion.

Supporters of the second "integrating" strategy remain utterly unconvinced by this and suggest completely inverting the approach: Conduct particle science by engaging the particles themselves in the cognitive process! This proposition sounds much less bizarre if the "particles" addressed are actually human beings. Therefore, discursive interaction with the specimens to be explored is imperative. In the context of Earth system science, sustainability research and climate change assessment, this tenet implies that the "stakeholder dialogue" (O'Riordan et al. 1999) is the prime mode of holistic knowledge production. Whether this notion can be properly put into operation, or whether it ultimately tends to pervert the classy scientific theatre into a self-referential "big brother" show for the masses remains to be seen.

Between the two poles portrayed, however, there are many intermediate ways of reconciling — or constructively combining, at least — the natural science and the social science methodologies. For example, one can adopt a semi-quantitative, semi-discursive approach as employed in the syndromes analysis of global change dynamics (Schellnhuber et al. 1997). The main idea is to identify typical functional patterns of environment-society interactions from stakeholder-informed phenomenological inspection and to model the pattern dynamics by qualitative differential equations expressing robust place-based observations. Thus precision is realized only to the degree that it can be justified, not to the extent it can be handled.

This intermediate approach is illustrated in Figure 1.2, which displays results of a semi-quantitative analysis of the Sahel-Syndrome dynamics in Northeast Brazil (Seitz et al., submitted). In this analysis, the crucial processes governing the development of smallholder agriculture in the region are symbolically modeled on the basis of a massive body of newly generated empirical data. Note that such an analysis can only provide the topology — not the metrics - of the temporal succession of system states; however, this information may already suffice for designing intervention strategies for syndrome mitigation.

Semi-quantitative, yet fully formalized techniques, such as the ones employed in syndromes analysis, hold a huge potential for the adequate scientific description of complex systems characterized by strong nature-society interactions. There is no point in feigning exactness by treating, say, the atmospheric component of these systems with scrupulous precision while, for example, the lifestyle aspects are dealt with in cavalier vagueness. The playing field for the clash of disciplines needs a bit of leveling, at least.

From the block of normative questions, let us select Question 16, which asks about the carrying capacity of the Earth, that is, the maximum number of people (at a given lifestyle) that the planet can support. This very question has been posed and answered many times since Antoni van Leeuwenhoek, the great 


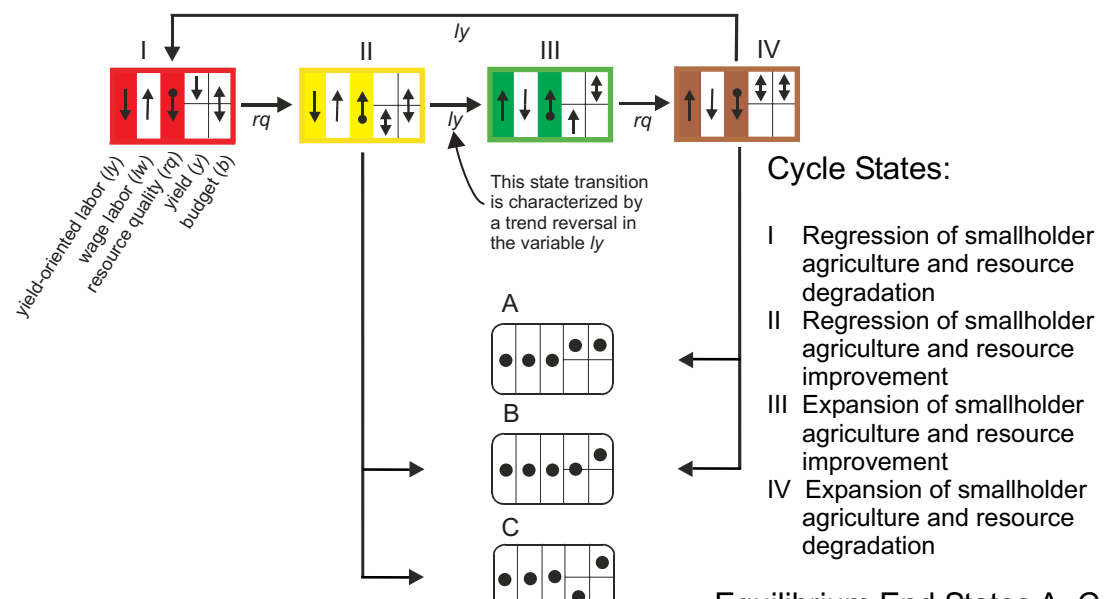

Equilibrium End States A-C

Figure 1.2 Symbolic dynamics of small agriculture in NE Brazil as a faithful projection to the five fundamental variables $l y$ (yield-oriented labor), $l w$ (wage-oriented labor), $r q$ (resource quality), $y$ (yield), and $b$ (budget). The two sets of boxes represent cycle states (I-IV) and equilibrium end states (A-C), respectively, expressing magnitudes and trends of the fundamental variables by appropriate symbols. Dots indicate that the variable is constant over time, whereas trends are indicated by directed arrows. The crucial $l y-r q$ trend combination is highlighted by color shading in the cycle state boxes. After Seitz et al., submitted.

Dutch scholar, provided the first serious estimate on April 25, 1679, in Delft: 13.4 billion. Unfortunately - and most interestingly — the sequence of subsequent estimates does not converge to a well-defined number, as Joel Cohen (1995a, b) has demonstrated (see Figure 1.3). In fact, the time series clearly exhibits the wild oscillations in the successive assessment numbers as well as the mostly increasing variability, which seems to peak in the science fiction-inspired decades after World War II. What is the explanation for this bewildering non-convergence of analysis? At least two factors have to be taken into account: First, there is the "supply side" of planetary carrying capacity, i.e., the totality of ecological services the Earth system can provide, including space, warmth, fresh air and fresh water, nutrition, shelter, and recreation (Millennium Ecosystem Assessment 2003). Our understanding of the structures and processes that determine the supply of these life-support items has dramatically grown, if not exploded, over the last 30 years, yet the number of riddles to be solved still appears to be almost infinite. For instance, nobody really knows the maximum sustainable protein yield of the world's oceans under ceteris paribus conditions, let alone under anthropogenic global warming. Without a full prognostic knowledge of the biogeophysical dynamics and the biogeochemical cycles involved, all of the figures put forward remain utterly elusive.

Second, there is the "demand side" of planetary carrying capacity, that is, the totality of ecological human needs that have to be satisfied according to 


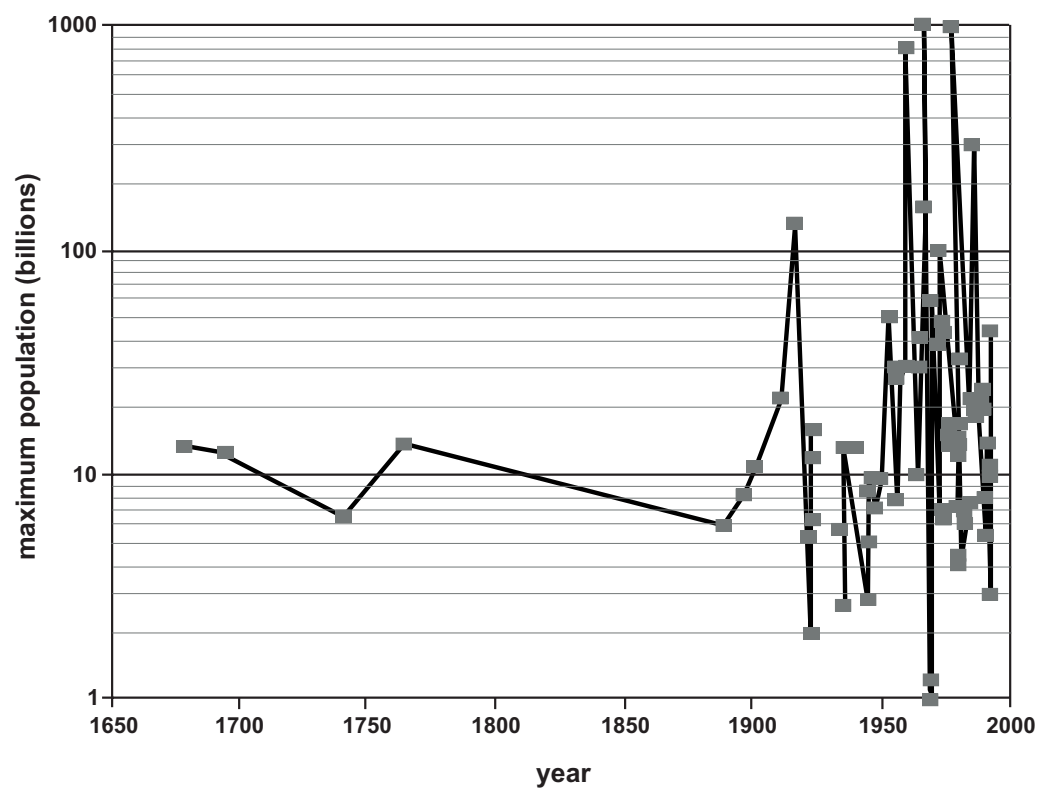

Figure 1.3 Time series representation of the historical assessment process regarding the human carrying capacity of the Earth. After Cohen (1995a, b).

judicious minimum standards. Who defines these standards? Dodging this awesome normative challenge by empirics does not help much, because one may calibrate the demand level either at the "American way of life" or at the subsistence needs of an Ethiopian farmer. To complicate matters, the ecological demand of $\mathrm{X}$ billion people is unlikely to equal the sum of $\mathrm{X}$ billion individual demands!

Thus, even the most unsophisticated approach to the Earth's carrying capacity boils down to calculating a ratio where both the numerator and the denominator are ill-defined. Still, Earth system science should provide a no-nonsense answer (or a sensible no-answer) to Question 16 to demonstrate its transdisciplinary worth.

To conclude our illustration of the Hilbertian program, let us consider Question 22, which asks about the options and caveats for top-down technologies supposed to fix global-scale sustainability problems. In recent years, there has been, for instance, a lot of discussion about the fantastically cheap and powerful geoengineering methods available to mitigate planetary warming; the world has also been told that genetic engineering of crops and entire ecosystems would turn the adaptation job almost into child's play. This seems to provide a dangerously overoptimistic picture biasing the mind-set of pragmatic decision makers, whereas solid opportunities may be dismissed precipitously by crucial parts of civil society in an intellectual backlash reaction. It is therefore the duty of the 

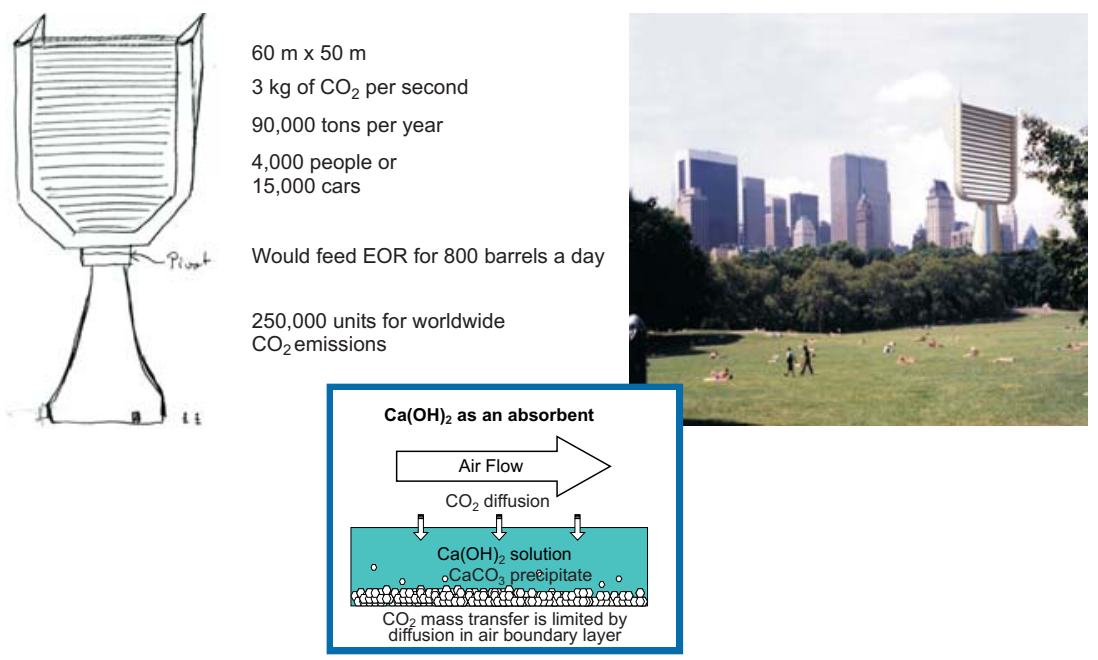

Figure 1.4 A not entirely tongue-in-cheek vision of future $\mathrm{CO}_{2}$ scrubbing, involving hundred thousands of macro-fans (courtesy of K. Lackner).

pertinent scientific community to explore carefully the possibility space of strategic schemes, including all its unconventional pockets, and to deliver a sober integrated assessment of the feasibility, effectiveness, efficiency, and acceptability of these schemes.

One remarkable attempt to meet this challenge was generated by the symposium on "Macro-engineering Options for Climate Change Management and Mitigation," organized by the Tyndall Centre and the Cambridge MIT Institute at the Isaac Newton Institute on January 7-9, 2004 (see http://www.tyndall.ac. uk/events/past_events/cmi.html). This event brought together experts from all relevant fields and institutions to discuss the profile of an optimal portfolio of macro-mitigation measures and potential macro-adaptation schemes (e.g., creating large-scale migration corridors for global warming-driven species and ecosystems) needed for coping with anthropogenic climate change.

One of the emerging ideas highlighted at the symposium was $\mathrm{CO}_{2}$ capture from ambient air to address the problem of emissions from diffuse sources (for an illustration, see Figure 1.4). As Earth system and sustainability science advances further, the assessment of top-down options for global change management will have to be revised at an accelerating pace, not dissimilar to the situation concerning the carrying-capacity question sketched above.

\section{SUSTAINABILITY SCIENCE}

The last half century has seen a number of transitions in how society views the relationships among environment, development, and knowledge. Only very 
recently, however, has it become evident that the Anthropocene crisis forces humanity to manage consciously a transition towards sustainable use of the Earth. Looking back over the last twenty years, few science-based ideas have risen from obscurity to take such a conspicuous position in international affairs as "sustainable development." Beginning shortly after the Rio Conference of 1992, however, it became increasingly clear that the enthusiasm with which much of the political world embraced sustainability ideas put environmental politics, negotiations, and agreements at center stage in the resulting debate, with science and technology relegated to the side wings if not thrown out altogether. At the same time, efforts to make progress in the implementation of sustainable development were increasingly being stalled by lack of technical knowledge rather than just weakness of political will: How could the decline in productivity for African agriculture be reversed while preserving biodiversity? How much greenhouse warming was too much? How could progress toward sustainability be reliably measured? The realization gradually began to sink in with the advocates of sustainability that all the negotiations in the world were not going to eaxct much progress on technical questions such as these.

In response to this mismatch of demand and supply, a number of efforts were initiated during the 1990s to reconsider how science might be better harnessed to achieve social goals of sustainable development in Vernadsky's would-be semi-intelligent "noösphere." The results of those efforts were synthesized as part of the international scientific community's input to the Johannesburg Summit (ICSU et al. 2002). One immediate outcome from this activity was the realization that the range of organized, disciplined, reflective activity needed for intelligently and effectively guiding a sustainability transition was much broader than what is conventionally subsumed under the term of "science." The Earth systems sciences noted above clearly have a role to play in promoting such a transition. So, however, does technology, innovation, and the tacit knowledge of practice. Even more broadly, there was clearly a need to mobilize the humanistic perspectives that would help us to understand where ideas about environment, development, and sustainability interacted with other dimensions of human thought about what we think we are and want to be. The term that has come closest to embracing this wide range of activities in English is "knowledge." Perhaps even more appropriate, within the backdrop of this Dahlem Workshop, is the German idea of Wissenschaft, embracing as it does the systematic pursuit of all knowledge, learning, and scholarship. Some of the key findings of this dialogue regarding what is needed from Wissenschaft - and the Wissenschaftler who pursue it - in a noösphere bent on sustainability are summarized below.

\section{Changing Orientations}

If Wissenschaft is to help advance sustainability, then a substantial part of our agenda needs to be driven by what society thinks it needs, not just by what 
scholars think is interesting (ICSU et al. 2002). This is not to advocate a return to sterile debates about the primacy of "basic" versus "applied," or "disciplinary" versus "interdisciplinary" research. Rather, it is to embrace the historical experience summarized by Donald Stokes (1997) in his book Pasteur's Quadrant: Basic Science and Technological Innovation, which argues that just as Pasteur created the field of microbiology in his pursuit of practical solutions to problems of great social importance, so it is possible today to do "cutting-edge research and development in the service of public objectives" (Branscomb et al. 2001). Which objectives is, of course, a matter of values - in this case values about what society actually means when it declares "sustainable development" to be a "high table" goal for the twenty-first century. Much debate has been expended in efforts to answer this question, and it is clear that different groups in society have reached different conclusions. Still, most of those debates share common concerns while differing largely in their emphasis on what is to be developed, what is to be sustained, what should be the relation of the developed to the sustained, and over how long a period the relationship should hold (see Figure 1.5).

At the international level, a broad consensus can be discerned that sustainable development should be development that, over the next two generations, promotes progress "to meet the needs of a much larger but stabilizing human population, to sustain the life-support systems of the planet, and to substantially

\begin{tabular}{|c|c|c|}
\hline $\begin{array}{l}\text { What is to be } \\
\text { sustained? }\end{array}$ & $\begin{array}{l}\text { For How Long? } \\
25 \text { years } \\
\text { "Now and in the future" } \\
\text { Forever }\end{array}$ & $\begin{array}{l}\text { What is to be } \\
\text { developed? }\end{array}$ \\
\hline $\begin{array}{l}\text { Nature } \\
\text { Earth } \\
\text { Biodiversity } \\
\text { Ecosystems }\end{array}$ & & $\begin{array}{l}\text { People } \\
\text { Child Survival } \\
\text { Life Expectancy } \\
\text { Education } \\
\text { Equity } \\
\text { Equal Opportunity }\end{array}$ \\
\hline $\begin{array}{l}\text { Life Support } \\
\text { Ecosystem Services } \\
\text { Resources } \\
\text { Environment }\end{array}$ & $\begin{array}{l}\text { Linked By } \\
\text { Only } \\
\text { Mostly } \\
\text { But } \\
\text { And } \\
\text { Or }\end{array}$ & $\begin{array}{l}\text { Economy } \\
\text { Wealth } \\
\text { Productive Sectors } \\
\text { Consumption }\end{array}$ \\
\hline $\begin{array}{l}\text { Community } \\
\text { Cultures } \\
\text { Groups } \\
\text { Places }\end{array}$ & & $\begin{array}{l}\text { Society } \\
\text { Institutions } \\
\text { Social Capital } \\
\text { States } \\
\text { Regions }\end{array}$ \\
\hline
\end{tabular}

Figure 1.5 Sustainable development: Common concerns, differing emphases. The U.S. National Research Council (NRC 1999, p. 24) produced this figure to summarize its exhaustive review of the different treatments of the sustainability concept present in the scholarly and political literature. 
reduce hunger and poverty" (NRC 1999, p. 31). Clearly, science, technology, and Wissenschaft more generally have roles to play in devising instrumental means to help reach these goals. In addition, however, society needs knowledge to help it discover what it means by what it believes it values. The scholarly community has done a much better job of this for the "development" side of sustainability than for the "environment" side (Parris and Kates 2003a, b). For example, we have so far given the policy world little help in articulating what it would mean, in specific terms, to "sustain the life-support systems of the planet." The implications of this shortfall for future research agendas are addressed in Working Group 4 (see Kinzig et al., Chapter 20, this volume).

A second major conclusion from recent efforts to reassess the role of Wissenschaft in promoting sustainability concerns questions of scale. The international consensus on broad sustainability goals is helpful as a general frame for discussions. Experience makes it clear that both the ends and the means of sustainable development need to be tailored or tuned to the context of particular places. This is, in part, because the basic ecological, climatic, and social structures that define sustainability needs and opportunities vary from place to place. It is also partly because some of the greatest threats to sustainability derive from "multiple, cumulative, and interactive stresses" (NRC 1999, p. 8) that intersect in particular ways in particular places. The importance of such place-based calibration became clear in the course of the Green Revolution, where initial efforts to transfer new varieties directly from international agricultural research centers to the field had to give way to systems of research and innovation that linked international centers to local crop improvement efforts through intermediary systems of national and regional agricultural research universities (Bell et al. 1994). Modern efforts to promote sustainability need to balance the scientific community's long-standing regard for knowledge that is universally true, with an appreciation of the fruits of multi-scale, integrated research that connects local, regional, and global perspectives to produce understanding that is true for specific places (E. Miles, pers. comm.).

Increasingly, it has become widely accepted that development in general, and sustainable development in particular, is a knowledge-intensive activity (World Bank 1999; UNDP 2001). However, a final insight to emerge from the last decade's reconsideration of the role of science in achieving sustainability is a shift of emphasis from the importance of "knowing" to the centrality of "learning." In part, this shift follows the reconceptualization of goals noted above. If sustainable development is about progress "to meet the needs of a much larger but stabilizing human population, to sustain the life-support systems of the planet, and to reduce substantially hunger and poverty," then sustainability itself can be thought of less as a state or condition and more as a direction or bias for development activities. This puts "sustainability" in the same camp as other great goals of the last century, such as "freedom" and "justice" - goals that we think more about moving toward than we do about achieving. If achieving sustainable 
development in some ultimate sense may seem problematic, promoting a transition toward sustainability should not (NRC 1999). An even more important reason for the shift of emphasis in sustainability thinking from "knowing" toward "learning" is simply that we have so much to learn. Understanding sustainability is understanding a complex, dynamic system of nature-society interactions - a system made all the more unpredictable by both our interest in what goes on in particular places and by our active, reflective engagement in the system whose behavior we are trying to predict. Trying to discover or write blueprints for such turbulent, rapidly evolving systems will in many cases prove futile. More important is that we recognize the extent of our ignorance, accept the concomitant necessity to treat policies and other management interventions as experiments, and take measures that will increase our prospects for surviving, and learning from, the experiments we are forced to conduct on ourselves. Sustainable development thus becomes viewed as a process of adaptive management and social learning in which knowledge plays a central role (Cash et al. 2003; Steffen et al. 2004, Chapter 6.5).

\section{Vulnerability Analysis: An Illustration of Sustainability Science}

As an example of the kind of knowledge needed from the sciences of sustainability, let us start with what we are trying to sustain. What would it mean to "sustain the life-support systems of the planet?" Such questions are very much on managers' and policy makers' minds, as suggested by the language about preventing "dangerous anthropogenic interference with the climate system" inserted into the Framework Convention on Climate Change. When science has been able to characterize unambiguously what constitutes "dangerous interference" with our environmental life-support systems, society has been reasonably successful in adjusting its behavior to remain within safe limits (e.g., the European use of "critical load" estimates for managing sulfur emissions and the risk of acid rain). Conversely, so long as opponents of management have been able to declare — as did U.S. President George W. Bush in opposing the Kyoto Protocol - that "no one knows what that (dangerous) level is" (press conference, June 11, 2001), science-based management remains a ready excuse for inaction. The S\&T community could therefore significantly improve "the prospects for humanity consciously managing a transition toward sustainability" by developing an understanding of the vulnerability and resilience of the Earth's life-support systems to "dangerous" disruption.

Early work on the "limits to growth," "Earth's carrying capacity," and "ecological footprints" addressed important issues but generally failed to develop a dynamic, causal understanding of how complex nature-society systems respond to stress. In contrast, more than a quarter century of serious scientific work on the resilience of ecological systems and the vulnerability of social systems has provided a solid foundation for such understanding. Recent efforts to 


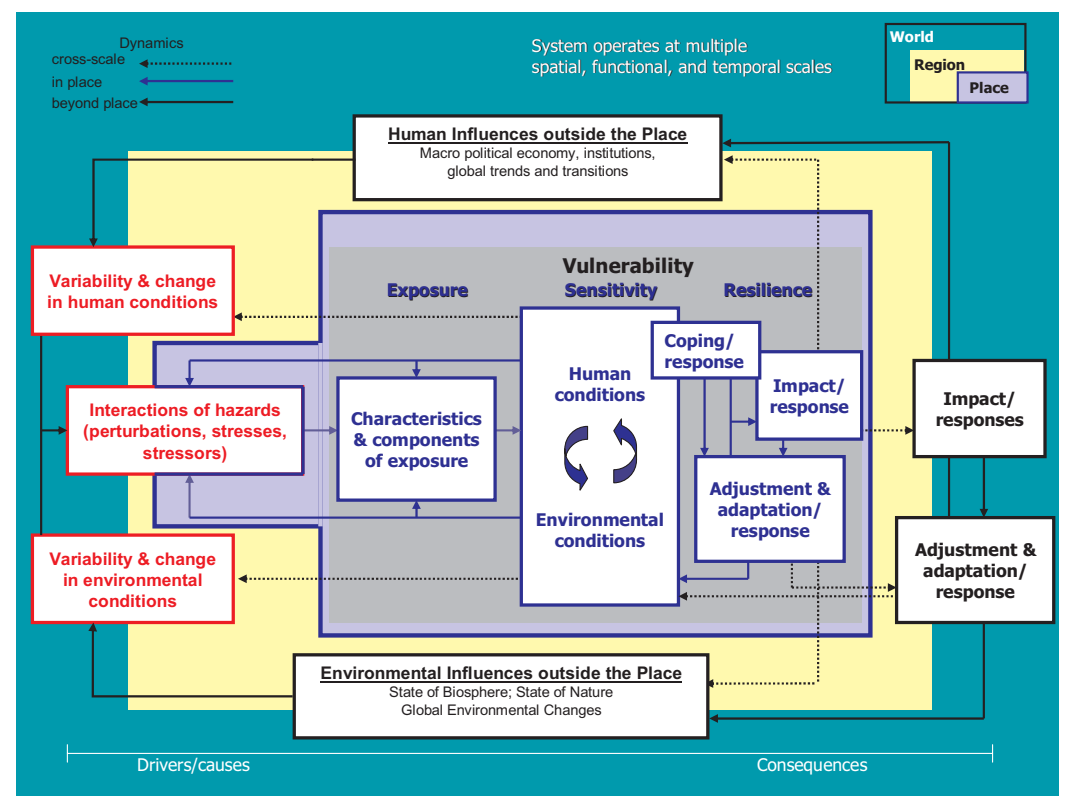

Figure 1.6 Vulnerability framework (Turner et al. 2003), summarizing the major elements of an emerging framework for analysis of vulnerability in coupled nature-society systems. It is explicitly scale-embedded and incorporates elements of exposure, sensitivity and resilience. Used with permission from the National Academy of Sciences, U.S.A.

synthesize those two historical strands of work have highlighted the importance of incorporating multiple stresses, teleconnections, explicit pathways of exposure, the possibility of threshold responses, explicit treatment of scale, and attention to the components of adaptive capacity in frameworks for the analysis of vulnerability and resilience (Turner et al. 2003; see Figure 1.6). These synthetic efforts have also drawn attention to the parallels between climatic and chemical "life-support systems" long discussed by Earth science researchers, the elements of "livelihood security" (e.g., access to and use of resources) stressed by development practitioners, and the newer emphasis by ecologists and resource economists on "ecosystem services." Needed now for management is problem-driven research that utilizes these conceptual vulnerability/resilience frameworks to illuminate the kinds, rates, and magnitudes of specific disturbances beyond which the "the ability of society to advance human well-being" can no longer be sustained.

\section{Guidance Systems for Sustainability}

We noted earlier the growing consensus that management systems for a sustainability transition need to be systems for adaptive management and social learning. The broad elements of such systems are reasonably straightforward: they 
require appropriate information, incentives, and institutions. What can Wissenschaft contribute to the development of such systems?

Information: Information is central to guidance, and guidance for a sustainability transition needs information on both where we want to go as well as how well we are doing at getting there. These are matters of setting goals and targets, defining indicators to track performance toward achieving them, and implementing the observational systems to measure the indicators. The scientific community has no monopoly on these tasks, but neither should it stand back and leave them wholly to others in the mistaken belief that to discuss the values inherent in the selection of goals and indicators is to lose scientific objectivity. Unfortunately, that is precisely what has happened for many of the sciences and scientists required to inform an intelligent social dialogue on goals and indicators of sustainability. Surprisingly, the situation is particularly grim with respect to the natural sciences. Whereas social scientists have been relatively successful at informing the debate on specific goals and indicators for the "meeting human needs" dimensions of sustainability, natural scientists have not contributed effectively to specifying goals and indicators for "protecting life-support systems." In a recent review of international efforts in this area, Parris (2003) found that only with respect to the global atmosphere was a reasonably integrated system of specific goals, targets, indicators, and monitoring in place. For the dimensions of "life-support systems" relating to ocean productivity, freshwater availability, land-use change, biodiversity, and toxic releases, no such system exists.

The call for problem-driven work on assessing vulnerability and resilience of the Earth's life-support systems noted above could provide the foundations for improvements in this area. However, even with improvements in the basic understanding of such key "life-support" concepts, a place-based strategy of goal-setting, indicator selection, and monitoring will still be needed for guiding the actions needed for a transition toward sustainability. More broadly still, the ultimate need is for a problem-driven, theoretically grounded, integrated approach for characterizing and measuring what we most value in coupled nature-society systems we inhabit. Partha Dasgupta (2001) has recently outlined one such an approach in his treatise on Human Well-being and the Natural Environment. The challenge for an emerging field of Earth systems analysis is to build on such frameworks, and to enrich them with our deepening understanding of how the biosphere - and noösphere - actually work.

Incentives: A second component of the guidance systems needed for managing a transition toward sustainability concerns getting the incentives right. How can people be induced to make production and consumption choices that are relatively less stressful to the environment than others that generate comparable increases in real well-being? How can perspectives incorporating long-term biosphere responses be appropriately factored into short-term social decisionmaking? More broadly, what is the right level and focus for the investments in 
the science, technology, and knowledge that are necessary for a transition toward sustainability? What sorts of inducements or feedback will best assure the provision of adequate constraint in individual human uses of nature's commons and of adequate investment in the "public goods" of ecosystem services?

When the economic costs and benefits of "sustainable" behaviors accrue to the same private parties, well-functioning markets perform admirably in aligning incentives and allocating society's investments. However, the real world is full of well-known features that undercut the efficacy of the market as an efficient allocator of investments in sustainability. These include distorting subsidies (e.g., to land clearing), mispriced environmental externalities (e.g., pollution), a strong public goods component of the social benefits provided by healthy environments (e.g., wetlands) and "clean" technologies (e.g., sewage treatment plants), the privatization of relevant data (e.g., genomics), and imperfect property rights regimes (e.g., fisheries). Although serious attention is being paid to each of these sources of "incentive failure," and a modest number of exciting new ideas have been broached in recent years (e.g., Sandler 1997), progress has been slow on both the theoretical and practical fronts. A concerted research and applications program on the incentives - market and otherwise that could fulfill Vernadsky's vision of an intelligently reflective, self-guiding "noösphere" is still badly needed.

Institutions: "Institutions" include the norms, expectations, rules, and organizations through which societies figure out what to do and organize themselves to do it. "Sustainability" itself is a norm, and thus part of the emerging institutional structure of Vernadsky's self-reflective noösphere. So are the international treaties and related arrangements that society has developed and deployed over the last several decades in hopes of bringing some degree of rational governance to the interaction of society with nature. Our focus here, however, is on the kinds of institutional reforms and innovations that are needed to harness science and technology better to the tasks of enabling and guiding a transition toward sustainability.

Such institutions are not impossible to design, as illustrated by experience in efforts to employ science and technology to enhance agricultural productivity, combat disease, and protect the global atmosphere. Such successes, however, have been partial, reversible, and idiosyncratic, producing little in the way of consensus on what sorts of institutional designs are most likely to enhance the use of knowledge to create an effectively reflective "noösphere." Over the last couple of years, however, consultations throughout the international community have identified a number of specific shortcomings in the present institutional system, and have proposed some directions in which reform efforts might usefully head. Below we address some of the crucial issues identified:

- Mobilizing the right knowledge: In the dialogues leading up to the Johannesburg Summit, one of the most persistent complaints was that today's 
agenda of $R \& D$ for sustainability reflects the priorities of global programs, disciplines, and donors more than it does those of the local decision-makers on who the prospects for sustainable development are so dependent. Moreover, it tends to devote much more attention to the identification of problems than the production of solutions (ICSU et al. 2002). What kinds of institutions can best improve the chances that research conducted in the name of sustainable development will actually focus on the most pressing problems as defined by relevant decision makers in the field? Institutions that can meet these challenges need one foot in the politics of problem definition, responsive to issues of appropriate participation and representation, and the other in the world of S\&T, responsive to issues of credibility and quality control. Few overtly "political" or "scientific" institutions seem to be able to perform such "boundary-spanning" functions effectively. A better record has been accumulated by organizations that explicitly cast themselves in a boundary-spanning role, responsible to the worlds of both knowledge and action, but not expected to conform fully to the norms of either (Cash et al. 2003). Examples include IIASA's "RAINS" effort to link S\&T with efforts to develop sustainable energy policy in Europe; a number of groups involved in making ENSO forecasts useful to decision-makers (IIAS 1992); and local organizations for technology innovation, such as India's Honey-Bee network. At their best, such institutions have facilitated two-way communication between experts and decision-makers, and provided neutral "sites" for the co-production of useful knowledge by scientists and problem-solvers.

- Integrating knowledges: Today's S\&T remains insufficiently inclusive and integrative to realize its full potential for helping with the complex, messy problems that need to be overcome in promoting a transition toward sustainability. What kinds of institutions can better integrate the "tacit" knowledge of practice (whether it be that of a cracking plant operator or a rice farmer) with the formal knowledge of laboratory science to produce practical insights on solutions to particular sustainability problems? How can the expertise of the private sector be integrated with that of the university and governmental S\&T communities to produce the public good of sustainable development without unacceptably undermining the incentives of business? How can the traditionally "island empires" of research, observations, assessment, and applications be better integrated into problem-solving systems of S\&T for sustainability? Examples of institutions that have successfully performed all of these desirable integrations are very few indeed. However, the community might usefully devote some attention to identifying effective models.

- Balancing flexibility and stability: The challenge of sustainable development is simultaneously long term and rapidly evolving. S\&T programs designed to promote sustainability need themselves to be sustained long 
enough to make a difference, but not at the cost of being stuck fighting the last war, or failing to learn from experience. No single institutional approach to this tension is likely to work everywhere. Some critical attention to which sorts of approaches is likely to be more effective under which kinds of circumstances seems long overdue. One response to the challenge of balancing flexibility and stability in R\&D agendas for sustainability has been to expand explicitly long-standing R\&D organizations, such as the International Agricultural Research Centers, to make them more responsive to emerging sustainability needs. Another is to assemble ad hoc task forces commissioned to address particular problems, for example the World Commission on Dams or the Millennium Ecosystem Assessment. A third particularly promising approach has been to combine the two models above, retaining a small professional secretariat to facilitate learning and the building of trust relations, but convening ad hoc teams to address particular problems. The Interacademy Panel on International Issues is an example of one institution seeking to pursue this approach.

- Infrastructure and capacity: Most of the world lacks the physical infrastructure and human capacity to do as well as it might in harnessing S\&T to sustainability. Additional investments, however, need to be strategically targeted if they are to improve the situation in an efficient manner. In particular, it seems clear that a balanced portfolio is needed that invests simultaneously in individuals, organizations, and networks. Furthermore, in those regions where basic education - the most fundamental source of R\&D capacity - is underdeveloped, priority must be given to building the educational base and enhancing an appreciation for the methods and potential contribution of science. Finally, a critically important infrastructure need is for institutions that support cross-scale linkages among researchers and problem-solvers. These need to be structured to facilitate both "vertical" connections between the best research anywhere in the world and the specific circumstances of particular field applications. At the same time they will need to foster "horizontal" connections among regional research and application centers to promote learning from one another. Precedents are rare, and even more rarely are they widely known.

\section{SCIENCE AND SOCIETY: A NEW CONTRACT FOR PLANETARY STEWARDSHIP?}

A remarkably productive "social contract" between society and the science community evolved throughout the industrialized and industrializing world in the latter half of the twentieth century. In essence, the contract held that society would invest heavily in basic science on the presumption that such investments would eventually result in better economic growth and national security. The stunning accomplishments of the original contract notwithstanding, it has 
become increasingly clear that for achieving many important social goals among them sustainable development - the original contract might be necessary but is certainly not sufficient. The result has been an increasing number of calls for "a new social contract for science," beginning with UNESCO's 1989 Conference on Science for the Twenty-first Century, focused by Jane Lubchenco's 1998 Presidential Address to the American Association for the Advancement of Science, and reaffirmed by the international science community in its preparations for the Johannesburg Summit on Sustainable Development (full citations in ICSU et al. 2002, p. 17).

The idea of the "new contract" has attracted a great deal of attention and has evolved in a number of parallel but not identical directions. Under most versions, however, the S\&T community would agree to devote an increasing fraction of its overall efforts to R\&D agendas reflecting society's goals for sustainable development. In return, society would undertake to invest an increasing fraction of its wealth to assure that science, technology, and Wissenschaft generally could be adequately mobilized to fulfill their role in guiding a transition toward sustainability, thus fulfilling their role in contributing to the informed governance of Vernadsky's noösphere. Moving from the intensely felt rhetoric of the "new contract" toward the practical reality of agendas for Earth system science and scientists - Wissenschaft and Wissenschaftleris a suitably ambitious challenge for a Dahlem Workshop.

\section{THE DAHLEM CONTRIBUTION}

The observations and considerations of the previous sections may be summarized in just one statement:

We are currently witnessing the emergence of a new scientific paradigm that is driven by unprecedented planetary-scale challenges, operationalized by transdisciplinary centennium-scale agendas, and delivered by multiple-scale co-production based on a new contract between science and society.

All crucial aspects of this statement were actually addressed at the $91^{\text {st }}$ Dahlem Workshop, held in May 2003, by an exceptional collection of scholars from all corners of the international scientific community. This volume presents the information that supported the meeting, condensed into sixteen state-of-the-art papers, as well as the pertinent results distilled into the group reports. The intimidating intellectual challenges involved were tackled in Dahlem by four working groups with a division-of-labor strategy roughly orienting itself by the successive qualitative stages of coevolution in the Earth system.

A remarkable clash of scientific cultures was staged in Group 1 (Lenton et al., Chapter 6), where researchers mainly concerned with geosphere-biosphere interactions on planet Earth met with astrobiologists primarily interested in the 
existence and habitability of other planets inside and outside the solar system. The common themes were the general possibility of (intelligent) life in our Universe and the long-term, large-scale coevolution of dead and living matter through complex self-organization processes far from thermodynamic equilibrium. The group addressed a number of exciting issues, such as the evolutionary topology of the biosphere, the interactive development of environmental dynamics and information processing through the great planetary transitions, the terraforming potential provided by Mars, the probability for the emergence of intelligence, and the failure of the SETI project (thus far) to track down messages from extraterrestrial civilizations. The GAIA theory (Lovelock 2000) served as an integrating factor and unifying metaphor in the group's debates.

Group 2 (Watson et al., Chapter 10) moved the analytic focus to what geologists might call the "recent planetary past," i.e., the Quaternary. The main idea was to scrutinize the Earth system machinery in a state as similar as possible to the contemporary one - yet without human interference with the relevant biogeophysicochemical inventories and processes. Special emphasis was given to the stability and variability of the Quaternary mode of operation of our planet, an analysis clearly involving the identification and quantification of major feedback loops, phase thresholds, and other critical elements. Not unexpectedly, a certain "row" between stability optimists (led by the geologists) and stability pessimists (led by the climatologists) took place in this group, resulting in very specific demands for high-quality data for settling the case. There was also agreement on the indispensability of major progress in Earth system modeling for understanding the roller-coaster dynamics of the Quaternary as illustrated by quasi-periodic glaciation episodes.

Almost everything on Earth has changed with the advent of Homo sapiens and the establishment of the modern anthroposphere. Group 3 (Steffen et al., Chapter 16) made the heroic effort to describe how the human factor has already modified the Quaternary mode of operation of our planet, to identify potential anthropogenic phase transitions lurking around the corner, to specify the scientific advancements necessary for timely anticipation of dangerous Anthropocene dynamics, and to assess the prospects of large-scale technological fixes of the accelerating sustainability crisis all around us. An in-depth analysis of the notorious climate sensitivity conundrum and a thorough delineation of "Earth system geography in the Anthropocene" (intercomparing the role of the mid-latitudes to the tropics and the polar regions) were among the highlights in the group's deliberations.

The most difficult task of all, however, remained for Group 4 (Kinzig et al., Chapter 20), who were to transgress the borderline between purely analytical reasoning and solution-driven strategic thinking. In other words, the group tried to identify pathways towards global sustainability, to evaluate the conceivable management schemes for steering our planet clear of the Anthropocene crisis, and to imagine all the scientific, technological, socioeconomic, and institutional 
innovations necessary for implementing the right strategy. Not surprisingly, a number of heated debates ensued when issues such as adaptive management; participatory decision making; integrated systems of production, consumption, and distribution; capacity building for coping with environmental change; and up-scaling of successful local/regional institutional designs were addressed. The discussions culminated in the group's attempt to sketch the crucial features of a future science-policy dialogue that allows for the true co-production of sustainability wisdom and to derive the pertinent conclusions for the novel organization of science and technology in the twenty-first century.

Altogether, the four groups actually succeeded in covering much of the vast terrain encompassed by the extraordinarily ambitious conference theme. Of course, there remain huge gaps and blatant superficialities, but all participants were convinced that this Dahlem Workshop was a milestone event that truly advanced Earth system analysis for sustainability. We hope that some of the excitement and inspiration that we experienced at Dahlem is conveyed by the following documentation.

\section{REFERENCES}

Annan, K. 2000. We, the Peoples: The Role of the United Nations in the 21st Century. New York: United Nations. http://www.un.org/millennium/sg/report/full.htm.

Ball, P. 2004. Critical Mass: How One Thing Leads to Another. Oxford: Heinemann.

Bell, D.E., W.C. Clark, and V.W. Ruttan. 1994. Global research systems for sustainable development: Agriculture, health and environment. In: Agriculture, Environment and Health: Sustainable Development in the $21^{\text {st }}$ Century, ed. V.W. Ruttan, 358-379. Minneapolis: Univ. of Minnesota Press.

Branscomb, L., G. Holton, and G. Sonnert. 2001. Science for Society: Cutting-edge basic research in the service of public objectives. http://www.cspo.org/products/reports/ scienceforsociety.pdf

Brown, H. 1954. The Challenge of Man's Future: An Inquiry Concerning the Condition of Man during the Years that Lie Ahead. New York: Viking Press.

Bunde, A., J. Kropp, and H.J. Schellnhuber, eds. 2002. Theories of Disaster: Scaling Laws Governing Weather, Body, and Stock Market Dynamics. Heidelberg: Springer.

Caldwell, L.K., and P.S. Weiland. 1996. International Environmental Policy: From the Twentieth to the Twenty-first Century. Durham: Duke Univ. Press.

Cash, D.W., W.C. Clark, F. Alcock et al. 2003. Knowledge systems for sustainable development. Proc. Natl. Acad. Sci. USA 100:8086-8091

Clark, W.C. 1989. Managing planet Earth. Sci. Am. 261(3):47-54.

Cohen, J.E. 1995a. How Many People Can the Earth Support? New York: W.W. Norton.

Cohen, J.E. 1995b. Population growth and Earth's human carrying capacity. Science 269:341.

Crutzen, P.J. 2002. The Anthropocene: Geology of mankind. Nature 415:23.

Dasgupta, P. 2001. Human Well-being and the Natural Environment. Oxford: Oxford Univ. Press.

Hansen, J. 2004. Defusing the global warming time bomb. Sci. Am. 290:68-77. 
Hilbert, D. 1901. Mathematische Probleme. Archiv der Mathematik und Physik 3:44-63, 213-237.

Humboldt, A. von. 1808. Ansichten der Natur mit wissenschaftlichen Erläuterungen. Tübingen: J.G. Cotta.

ICSU, TWAS, and ISTS (Intl. Council for Science, Third World Academy of Science, and Initiative on Science and Technology for Sustainability). 2002. Science and Technology for Sustainable Development. Series on Science for Sustainable Development, vol. 9. Paris: Intl. Council for Science. http://www.icsu.org/Library/WSSDRep/Vol1.pdf.

IIASA (Intl.Institute for Applied Systems Analysis). 1992. Science and sustainability: Selected papers on IIASA's $20^{\text {th }}$ anniversary, p. 1. Laxenburg: IIASA.

IPCC (Intergovernmental Panel on Climate Change). 2001. Climate Change 2001: The Scientific Basis. Working Group I to the Third Assessment Report of the IPCC, ed. J.T. Houghton, Y. Ding, D.J. Griggs et al. Cambridge: Cambridge Univ. Press.

IUCN (Intl. Union for the Conservation of Nature). 1980. World Conservation Strategy: Living Resource Conservation for Sustainable Development. Gland: IUCN.

Kates, R.W. 2001. Queries on the human use of the Earth. Ann. Rev. Energy Environ. 26: $1-26$.

Kates, R.W., and T.M. Parris. 2003. Long-term trends and a sustainability transition. Proc. Natl. Acad. Sci. USA 100:8062-8067.

Loutre, M.F., and A. Berger. 2000. Future climatic changes: Are we entering an exceptionally long interglacial? Clim. Change 46:61-90.

Lovelock, J.E. 2000. The Ages of Gaia. Oxford: Oxford Univ. Press.

Lovelock, J.E. 2003. Gaia: The living Earth. Nature 426:769-770.

Marsh, G.P. 1864. Man and Nature: Or, Physical Geography as Modified by Human Action. New York: Scribner.

Marsh, G.P. 1965. The Earth as Modified by Human Action. Harvard: Harvard Univ. Press., Belknap Press.

McNeill, J.R. 2000. Something New under the Sun: An Environmental History of the Twentieth-century World. New York: W.W. Norton.

Millennium Ecosystem Assessment. 2003. Ecosystems and Human Well-being: A Framework for Assessment. Washington, D.C.: Island Press.

Mitchell, R.B. 2003. International environmental agreements: A survey of their features, formation, and effects. Ann. Rev. Env. Resour. 28: 429-461.

Moore, B., III, A. Underdal, P. Lemke, and M. Loreau. 2002. The Amsterdam declaration on global change. In: Challenges of a Changing Earth, ed. W. Steffen, J. Jäger, D.J. Carson, and C. Bradshaw. Heidelberg: Springer.

Nowotny, H., P. Scott, and M. Gibbons. 2001. Re-thinking Science: Knowledge Production in an Age of Uncertainty. Cambridge: Polity Press.

NRC (National Research Council). 1999. Our Common Journey: A Transition toward Sustainability. Washington, D.C.: Natl. Acad. Press.

O'Riordan, T., J. Burgess, and B. Szerszynski. 1999. Deliberative and Inclusionary Processes: A Report from Two Seminars. CSERGE Working Paper: PA 99-06. Centre for Social and Economic Research on the Global Environment, Univ. of East Anglia, Norwich, U.K.

Parris, T.M. 2003. Toward a sustainability transition. Environment 45:13-22.

Parris, T.M., and R.W. Kates. 2003a. Characterizing a sustainability transition: Goals, targets, trends, and driving forces. Proc. Natl. Acad. Sci. USA 100:8068-8073.

Parris, T.M., and R.W. Kates. 2003b. Characterizing and measuring sustainable development. Ann. Rev. Energy Environ. 28:559-586. 
Pauly, D., and V. Christensen. 1995. Primary production required to sustain global fisheries. Nature 374:255-257.

Royal Society of Chemistry (Great Britain). 2003. Sustainability and Environmental Impact of Renewable Energy Sources. Issues in Environmental Science and Technology 19. Cambridge: Royal Society of Chemistry.

Ruddiman, W.F. 2003. The anthropogenic greenhouse era began thousands of years ago. Clim. Change 61:261-293.

Sandler, T. 1997. Global Challenges: An Approach to Environmental, Political, and Economic Problems. Cambridge: Cambridge Univ. Press.

Sahagian, D., and H.J. Schellnhuber. 2002. GAIM in 2002 and beyond: A benchmark in the continuing evolution of global change research. Global Change Newsl. 50:7-10.

Schellnhuber, H.J. 1999. "Earth system" analysis and the Second Copernican Revolution. Nature 402(2):C19-C23.

Schellnhuber, H.J. 2002. Coping with Earth system complexity and irregularity. In: Challenges of a Changing Earth, ed. W. Steffen, J. Jaeger, D.J. Carson, and C. Bradshaw, pp. 151-159. Berlin: Springer.

Schellnhuber, H.J., A. Block, M. Cassel-Gintz et al. 1997. Syndromes of global change. GAIA 6:19-34.

Schellnhuber, H.J., and D. Sahagian. 2002. The twenty-three GAIM questions. Global Change Newsl. 49:20-21.

Steffen, W.L. 2002. Challenges of a changing Earth. Proc. Global Change Open Science Conf., Amsterdam, July 10-12, 2001. Global Change, IGBP Series. Berlin: Springer.

Steffen, W., J. Jäger, D.J. Carson, and C. Bradshaw, eds. 2002.The Challenges of a Changing Earth. Heidelberg: Springer.

Steffen, W. et al., eds. 2004. Global Change and the Earth System. Heidelberg: Springer.

Stokes, D. 1997. Pasteur's Quadrant: Basic Science and Technological Innovation. Washington, D.C.: Brookings Institution.

Stoppani, A. 1873. Corso di geologia. Vol. II. Milan: G. Bernardoni E.G. Brigola.

Thomas, W.L. 1956. Man's Role in Changing the Face of the EARTH. Chicago: Published for the Wenner-Gren Foundation for Anthropological Research and the National Science Foundation by the University of Chicago Press.

Turner, B.L. II, et al. 1990. The Earth as Transformed by Human Action. Cambridge: Cambridge Univ. Press.

Turner, B.L., II, R.E. Kasperson, P.A. Matson et al. 2003. A framework for vulnerability analysis in sustainability science. Proc. Natl. Acad. Sci. USA 100:8074-8079.

UNDP (United Nations Development Programme). 2001. Making New Technologies Work for Human Development. Oxford: Oxford Univ. Press.

Vernadsky, V.I. 1945. The biosphere and the noösphere. Am. Sci. 33:1-12.

Vernadsky, V.I. 1998. The Biosphere (translated and annotated version from the original of 1926). New York: Copernicus, Springer.

WCED (World Commission on Environment and Development). 1987. Our Common Future. Oxford: Oxford Univ. Press.

World Bank. 1999. Knowledge for Development: The World Development Report for 1998/1999. Washington, D.C.: The World Bank.

Zickfeld, K. 2003. Modeling large-scale singular climate events for integrated assessment. Ph.D. Thesis, University of Potsdam. 